\title{
DESMONTAGEM CÊNICA: reflexão sobre o processo ético e estético do artista-docente
}

\author{
SCENIC DISASSEMBLY: \\ reflections about the ethical and aesthetic process of the artist-teacher
}

José Raphael Brito dos Santos ${ }^{1}$

\section{RESUMO}

Este artigo discute as novas possibilidades da cena contemporânea, tendo em vista, a desmontagem cênica como estratégia de reflexão e discussão na formação do artista-docente. Na primeira parte, tem como objetivo apresentar questionamentos e conceitos acerca das práticas teatrais na cena contemporânea e os diferentes modos de criação e investigação. $\mathrm{Na}$ segunda parte, aborda a desmontagem cênica e seus possíveis fundamentos conceituais, com base na escassa referência, colocando este fundamento como reflexão ética e estética. Por fim, apresenta um compartilhamento escrito da desmontagem "Experiências do sensível: travessias artísticas" realizada na disciplina "Pedagogia(s) do teatro: práticas contemporâneas", ministrada pela Professora Dra. Mara Leal, no Programa de Pós-Graduação em Artes/Mestrado, do Instituto de Artes da Universidade Federal de Uberlândia, em 2013.

Palavras-chave: Desmontagem, Cena Contemporânea, Ético, Estético, Artista-Docente.

\section{RESUMEN}

Este artículo aborda las nuevas posibilidades de la escena contemporánea a la vista, el desmontaje escénica como la reflexión y el debate sobre la formación de la estrategia de artista-docente. La primera parte tiene como objetivo presentar las preguntas y conceptos acerca de las prácticas teatrales en la escena contemporánea y los diferentes modos de creación y la investigación. La segunda parte aborda el desmontaje escénica y posibles fundamentos conceptuales, basadas en escasa referencia, poniendo esta fundación como una reflexión ética y estética. Por último, presenta un desmantelamiento por escrito compartir "experiencias sensibles: los cruces artísticos", celebrado en la disciplina "Pedagogía (s) del teatro: las prácticas contemporáneas", impartido por el profesor Dr. Mara Leal, en lo Programa de Postgrado en Artes / Master, el Instituto de Artes de la Universidad Federal de Uberlandia, en 2013.

Palabras clave: Desmontaje, Escena Contemporánea, Ética, Estética, Artista-Docente.

\begin{abstract}
This article discusses the new possibilities of the contemporary scene in view, the scenic disassembly such as reflection and discussion on formation of artist-teaching strategy. The first part aims to present questions and concepts about the theater practices in the contemporary scene and the different modes of creation and research. The second part addresses the scenic disassembly and possible conceptual foundations, based on scant reference, putting this foundation as an ethical and aesthetic reflection. Finally, presents a written sharing dismantling "Experiences sensitive: artistic crossings" held in the discipline "Pedagogy (s) of the theater: contemporary practices", taught by

\footnotetext{
1 Universidade Federal de Uberlândia - UFU. Programa de Pós-Graduação em Artes/Mestrado, do Instituto de Artes. Estágio da Pesquisa: Projeto em Andamento (2013-2014). Área de Pesquisa: Práticas e Processos em Artes. Orientação: Prof. Dr. Narciso Telles. Fomento: Bolsa Capes. Ator e Pesquisador nas seguintes áreas: Cena contemporânea; Treinamento do ator; Pedagogia do artista; Processos de criação em artes cênicas; Experiência cênica; Teatro de Grupo. Email: raphaelbryto@gmail.com.
} 
Professor Dr. Mara Leal, in the Program of Post-Graduation in Arts / Master, the Institute of Arts of the Federal University of Uberlandia, in 2013.

Keywords: Disassembly, Contemporary Scene, Ethical, Aesthetic, Artist-Teaching.

Como pesquisar os processos criativos? Quais as possibilidades de investigação das práticas teatrais contemporâneas? Existem métodos ou modos? Qual o não-lugar do artista-docente na contemporaneidade? O que é desmontagem cênica? Quais os modos de reflexão desenvolvidos na cena teatral na atualidade?

Este artigo e as perguntas anteriores surgem como provocações acerca das novas possibilidades de reflexão e investigação do saber da cena, a partir das recentes práticas e reflexões teatrais na contemporaneidade.

Portanto, faz-se necessário iniciar a discussão, mapeando o lugar da cena contemporânea e suas novas possibilidades como campo de investigação para apresentação da desmontagem cênica e, consequentemente, dos aspectos que norteiam essa estratégia de demonstração dos processos de criação. Permitindo, ao final da discussão, um levantamento de questões que viabilizam o campo ético e estético na reflexão sobre o artista-docente.

\section{CENA CONTEMPORÂNEA: sobre rasuras e rascunhos}

O processo de criação das práticas teatrais na cena contemporânea têm se configurado em exercícios artísticos e propostas com laboratórios e experiências cênicas, que não visam à formulação clássica, no território da morfologia acabada, que denomina o campo tradicional no teatro. Sendo assim, as práticas contemporâneas têm se configurado, em sua maioria, em tendências que mobilizam a criação por meio da fruição e da capacidade estética em realizar percursos artísticos sob a ótica da espontaneidade, investigação e do trabalho colaborativo.

Além disso, “os conceitos e as teorias vão sendo construídos com base na prática dos artistas que, [...] se utilizam de procedimentos híbridos, num cruzamento com outras linguagens" (LEAL, 2013, p. 200). As práticas cênicas se apresentam como dispositivo de intermediação que sofrem constante tensão e transformação, e por isso, os novos procedimentos de investigação e criação dão lugar para novas tendências e pensamentos discursivos.

Neste sentido, o teatro contemporâneo trata de manifestações e acontecimentos cênicos atuais que, geralmente, estão em contraposição ao drama clássico, ao modelo de convenção teatral, à manipulação do espectador, à poética clássica e à imitação de um estado de mundo da ação 
humana que, por vezes, desconsideram as novas práticas teatrais, como a autonomia do espectador e do ator-criador no processo cênico (PAVIS, 2010).

O teatro contemporâneo apresenta dispositivos na cena, que fazem usos de códigos, signos, textos, leituras, imagens, perspectivas e apropriações, nas quais ativam a capacidade interpretativa do espectador, que está atento, não somente, ao resultado da manifestação teatral, mas também ao processo e ao "movimento criador", que deu sentido ao estado de criação cênica (SALLES, 2009, p. 11).

As práticas teatrais contemporâneas questionam os estreitos limites da criação e investigação da cena, ao mesmo tempo em que apresentam novas possibilidades de pesquisa em teatro, discutindo novos objetos-sujeitos, métodos-modos e criação-investigação artística. Desta forma, caro leitor, coloco as palavras anteriores com hífen, para situar o não-lugar dos próprios conceitos nas teorias teatrais, com o objetivo de nos provocar enquanto artistas-pesquisadores da área.

Neste contexto, as práticas teatrais contemporâneas têm provocado uma discussão que afeta diretamente os modos de agir, pensar e investigar os processos cênicos. Estas questões têm direcionado os discursos teóricos e as práticas investigativas, como afirmam os autores na citação a seguir.

\footnotetext{
La investigación en artes escénicas representa un campo emergente de investigación que trata de abordar los nuevos fenómenos y transformaciones que se operan en el pensamiento y en las prácticas escénicas contemporáneas, implicando a sus participantes y asumiendo que las interrelaciones que se producen entre el sujeto y el objeto de la investigación forman parte sustancial de la misma (BILBAO; MARTÍNEZ; JIMÉNEZ, 2013, p. 4).
}

Levando em consideração a afirmação anterior, os fenômenos da cena contemporânea, tem proporcionado o surgimento de novos campos investigativos, que viabilizam novas tendências e práticas, e produzem suportes para estratégias inovadoras de discurso e pensamento na investigação cênica.

Vale ressaltar que, neste artigo, os novos procedimentos de pesquisa e criação não estão categorizados no espaço hierárquico de poder e valorização teórica, mas de possibilidades que surgem no decorrer das práticas artísticas. Ou seja, a cena contemporânea pode ser considerada como "una investigación de las condiciones de posibilidad, un discurso que se refiere a las formas de conocimiento y juicio de las condiciones de posibilidad" (RANCIÈRE, 2010, p.89).

A reflexão da cena na atualidade está diretamente ligada ao processo, esboço e movimento da criação cênica, que tem a investigação, como ponto primordial de análise. Em 
contraposição com a ideia de resultado e produto da obra acabada que, frequentemente, tem por objetivo o discurso generalizado e universal.

As práticas cênicas se transformam em estratégias que tratam de indagar, através do próprio processo criativo, as condições de funcionamento do discurso, que está movido pela competência, razões, paixões e motivos do processo criativo, colocando em discussão a decomposição ou desmontagem da cena como suporte e aspecto investigativo que geram reflexões, acerca de ferramentas que proporcionam adentrar um território de invenções e competências na cena.

\section{DESMONTAGEM CÊNICA: poética do avesso}

Levando em consideração os processos criativos, a encenação contemporânea e os motivos pessoais que provocam e movem o artista da cena para a investigação e construção da obra de teatro, tem-se como possibilidade de reflexão, o que tem se denominado de Desmontagem Cênica. Este procedimento pode ocorrer de vários modos em contextos múltiplos, com o objetivo de desvendar os processos de pesquisa e montagens de espetáculos, apresentando suas tessituras e percursos criativos. Esta apresentação ocorre a partir da escolha que o artista faz em mostrar ou ocultar os procedimentos criativos surgidos no decorrer da criação de um espetáculo.

Portanto, caro leitor, a caráter de esclarecimento prévio, devido o pouco repertório teórico de discussão deste conceito, as considerações a seguir, fazem parte de uma estruturação de ideias, apresentadas por Ileana Diéguez (2010) em seus artigos colocados na referência deste trabalho, assim como, suas considerações feitas no "III InterFaces Internacional - Intercâmbio em Artes Cênicas: A desmontagem como procedimento artístico-pedagógico" ${ }^{2}$, organizadas e sistematizadas pelo pesquisador nas linhas que se seguem, com breves reflexões.

Deste modo, para se discutir a desmontagem cênica, faz-se necessário destacar que sua prática no exercício da cena e na teoria epistemológica, surgiu na América Latina, com grupos de teatro latino-americanos na década de 80, em cidades como Lima e Havana, que apresentavam demonstrações técnicas de trabalho ou desmontagens cênicas de seu repertório, assim como, as demonstrações de trabalho de Odin Theatre.

${ }^{2} \mathrm{O}$ "III InterFaces Internacional-Intercâmbio em Artes Cênicas: A desmontagem como procedimento artísticopedagógico", ocorreu na Universidade Federal de Uberlândia-UFU, entre 15 e 18 de abril de 2013, organizado pelo Grupo de Estudos e Investigações Sobre Criação e Formação em Artes Cênicas (GEAC). 
Estas novas práticas cênicas surgiram por demonstrações de grupos, que apresentavam suas encenações baseadas na teatralidade contemporânea, distanciando-se das formas tradicionais de produção e representação, caracterizados pela influência de discursos estéticos não oficializados pela prática teatral tradicional, surgindo então, o exercício de exposição dos processos de trabalho.

As apresentações dos processos de pesquisa cênica se preocupavam em mostrar não somente os resultados dos trabalhos, mas também partilhar processos de construção, produção e investigação da tessitura cênica, originando acontecimentos artístico-pedagógicos. Desta forma, estes eventos se constituíram como um modo particular de apresentar os processos de trabalho, sem se enquadrar em um sistema fechado, acabado e totalizado a regras.

$\mathrm{Na}$ desmontagem cênica são colocados em questão o compartilhamento de investigações, experimentações e confrontos, sejam na esfera política e artística, oriundos do processo de montagem em caráter ético e estético.

Segundo Ileana (2010), esse procedimento de trabalho chamado desmontagem, apresenta suas proximidades com a demonstração técnica de trabalho, mas ao mesmo tempo, têm características e consonâncias problematizadas a partir dos conceitos apresentados por Derrida (1995), que coloca a ação de decompor e desmontar estruturas, e que remete a prática filosófica aplicada aos textos da linguística, literatura e todos os métodos e sistemas de poder seguidos de uma concepção fechada e estruturada.

Sendo assim, apresenta o antiestruturalismo como ação de decompor as estruturas e modelos acabados. Portanto, desmontar não é desconstruir o processo cênico, mas desvendar o percurso da cena e promover o diálogo com o próprio processo de trabalho. $\mathrm{O}$ artista revela seus procedimentos do processo de criação, e torna-se o próprio investigador que problematiza sua montagem.

Na desmontagem se apresenta o reflexo das memórias que são tecidas por palavras, como um conjunto de ideias verbais, visuais, textuais, sonoras, dentre outros. Portanto, ao pensar no roteiro de apresentação da desmontagem, o artista reconfigura sua vida a partir de suas memórias e arquivos, ou seja, não existe método pronto e acabado para organização da desmontagem.

Pelo contrário, a decomposição do processo criativo está para além de desvendar o virtuosismo e os procedimentos técnicos do artista, mas revela o pensamento político e as provocações do seu percurso criativo.

O artista apresenta, por assim dizer, uma espécie de seminário aberto teórico-prático, como afirmou Ileana Diéguez em uma de suas palestras no "III Interfaces Internacional - 
Intercâmbio em Artes Cênicas", que é formulado e roteirizado em caráter particular, e configura seu próprio percurso na apresentação da desmontagem, pois não há regras e esboços acabados na concepção do roteiro.

\begin{abstract}
No existe un método para los desmontajes, no es possible fijarlos em um esquema que ossifique el cuerpo vivo de la escena. Cada creador elige las estratégias desde las cuales aceder o regressar a ese encuentro reflexivo y a la vez artistico con su proprio material. A través de diversas experiencias, los desmontajes han integrado el discurso pedagogico, las demonstraciones verbalizadas, las explicaciones teóricas, y también se han materializado como desensamblages visuales e conceptuales. (DIÉGUEZ, 2010, p. 145).
\end{abstract}

Ao decompor a cena do processo criativo, o artista estabelece uma estratégia única de apresentação dos fatos que teceram o processo de criação. $O$ desnudamento da cena que $o$ procedimento da desmontagem provoca revela o modo de fazer, o percurso e o movimento criador do artista, diante do caos. Portanto, não se pretende analisar o processo criativo, mas colocar a exposição dos afetos, motivos, paixões e provocações. É importante destacar também que o desvelamento e o ocultamento são fatores presentes no procedimento da desmontagem, neste caso, as escolhas próprias do artista revelam diretamente seu modo de fazer, pensar e agir nos seus processos criativos.

Não estabilizada na forma precisa e fechada, a desmontagem abre a noção de ritual e experiência particular que cada artista tem diante de sua obra, ou seja, o artista como criador e pensador da filosofia da composição, parafraseando Edgar Poe (1999). A desmontagem coloca o artista diante do acontecimento que vê a vida, e o coloca diante do Humano que ele é, e suas questões diante do mundo.

Portanto, é um compartilhamento de experiência em forma de artigo vivo, em que o artista é o sujeito da experiência, "um sujeito ex-posto, ou seja, receptivo, aberto, sensível e vulnerável. [...] um sujeito que não constrói objetos, mas que se deixa afetar por acontecimentos". (LARROSA, 2008, p. 187). E com referência nesses acontecimentos, desnuda suas várias capas e vai revelando suas vontades, anseios, desejos e tensões.

$\mathrm{Na}$ demonstração técnica se revelam práticas gerais sobre o processo de construção e criação dos procedimentos que viabilizam a construção da montagem e dos aspectos técnicos que norteiam a dimensão criadora. Já na desmontagem, o pensamento micro e específico é o fator preponderante neste procedimento, com segredos, questões, dúvidas, passos e descompassos que apresentam detalhamentos do percurso criativo. 
A desmontagem torna presente o que estava ausente; convoca e incorpora os vestígios e os principais motivos que compõem a obra cênica. É o lugar do testemunho vivo do artista para o público no contexto que promove o encontro afetivo, pessoal e documental.

Ou seja, promove não só a partilha do trabalho do artista, mas o [com]partilhamento do artista como ele é. Portanto, é um procedimento artístico-pedagógico, na medida em que promove um procedimento do encontro, como afirmou Ileana Diéguez em uma de suas palestras no "III Interfaces Internacional - Intercâmbio em Artes Cênicas”.

\section{ENTRE O ÉTICO E O ESTÉTICO: Travessias Artísticas}

Neste tópico, apresento breve relato da minha primeira experiência na apresentação da desmontagem cênica intitulada "Experiências do sensível: travessias artísticas", apresentada no dia 29 de maio de 2013, às 10 e meia da manhã, na disciplina "Pedagogia(s) do teatro: práticas contemporâneas.

A desmontagem a seguir teve como objetivo relatar e desvendar o meu percurso artístico enquanto pesquisador e fazedor de teatro, desde as minhas primeiras experiências cênicas: o período na graduação em Teatro, de 2007 a 2012 e as pesquisas artísticas desenvolvidas; o trabalho monográfico; os espetáculos "Primeiro Amor" e "Siameses"; e por fim, a reflexão da influência dessas vivências na minha pesquisa atual sobre a formação do artista-docente, a partir dos processos de criação da cena, investigado no referido programa de pós-graduação, citado anteriormente.

A desmontagem foi apresentada em o que denominei de cinco estações: [1] Pedreiras, interior do Maranhão; [2] UFMA - Universidade Federal do Maranhão; [3] Monografia; [4] Espetáculo "Primeiro Amor"; [5] Espetáculo "Siameses".A cinco estações foram ilustradas por escrito em papel cor de terra, coloração da qual me identifico muito, e colocadas na parede como mostra a figura abaixo; ao passo em que eu dialogava sobre a estação "x", esta era iluminada, como mostra a figura abaixo.

O público entrou ao som de uma música "Travelling” que possui suspiros, ruídos e vozes polifônicas, da compositora, performer, diretora, vocalista, cineasta e coreógrafa americana Meredith Monk (1981). Esta sonoridade simbolizou a não linearidade, o recorte, a fragmentação e a decomposição do meu percurso de vida, como artista e como ser humano. 


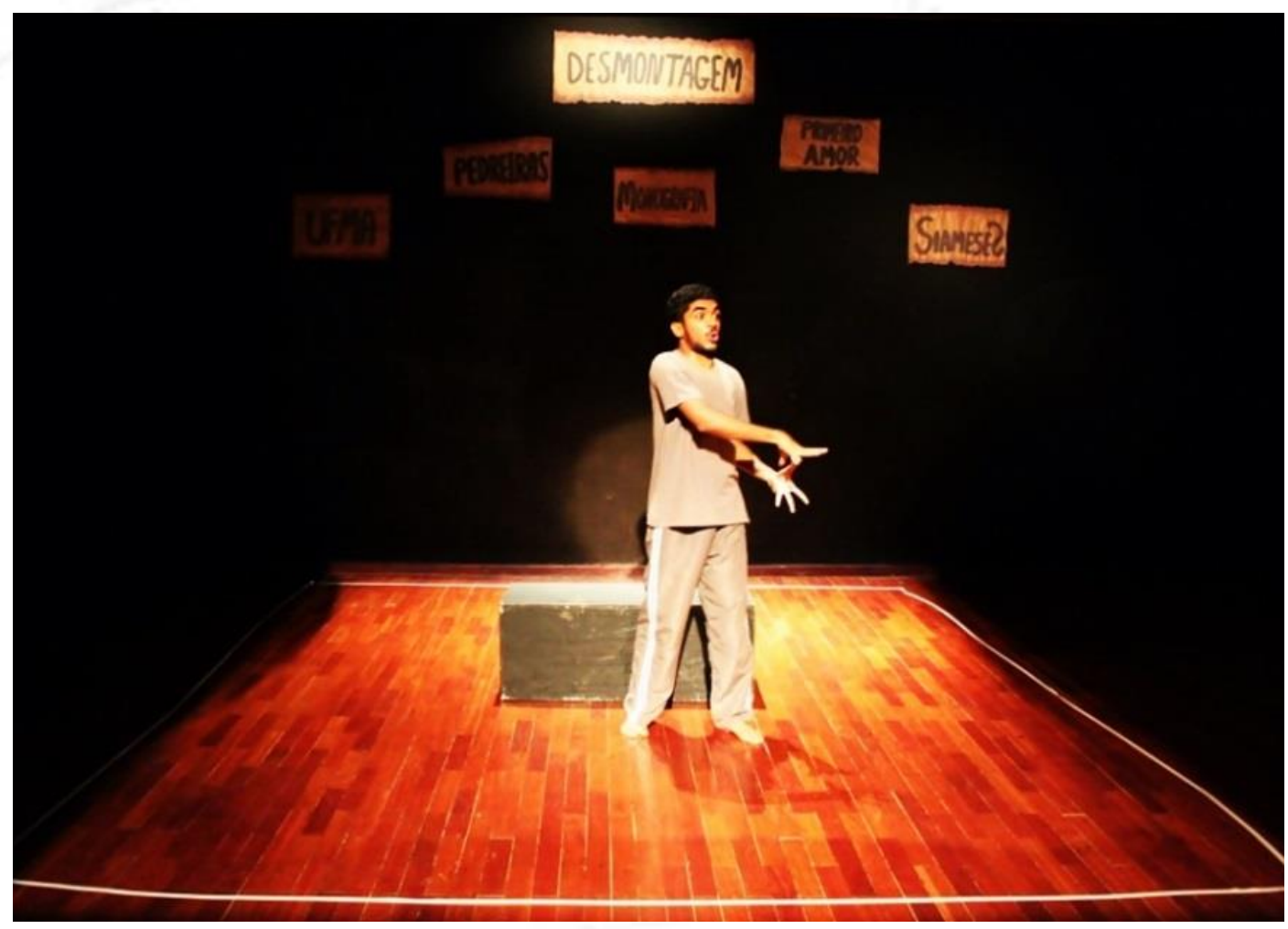

Figura 1 / Desmontagem / Fotografia: Jarbas Siqueira

Na estação [1] Pedreiras, interior do Maranhão relatei a minha primeira experiência com o "teatrinho na escola" no ensino médio nos anos de 2004, 2005 e 2006. O Grupo de Teatro GTESF (Grupo de Teatro São Francisco), do qual fiz parte, apresentou cinco peças diferentes durante esses três anos de colegial. Lembro que a minha noção sobre o teatro era decorar o texto e apresentar no auditório da escola, tendo como referência de aprendizado a interpretação dos atores em filmes e novelas, realista e naturalista. Nesta época, comecei a me questionar sobre meu futuro e minha profissão. Em contraponto, momento também de muita tristeza, ao ver que alguns dos meus melhores amigos não concordaram com minha escolha profissional. Frustrante e, ao mesmo tempo, estimulante. E com tudo isso, entrei na faculdade. 
Na estação [2] UFMA (Universidade Federal do Maranhão): citei as principais produções no decorrer da graduação na universidade e a influência das disciplinas de caráter prático na minha formação. Erros e acertos, aprendizados e momentos tensos dos processos criativos. A experiência que tive em diversos grupos de pesquisa prática com estéticas e metodologias de trabalho diferentes, como: performance; teatro documentário; espetáculo com drama clássico; espetáculo com construção de dramaturgia coletiva; processos colaborativos, dentre outros. Nesta época, me deparei com disciplinas pedagógicas e na situação de ministrar minha primeira aula ou oficina enquanto aprendiz docente. Percebi que minhas referências estavam em meu próprio corpo, marcas, vivências, e sensações, ou seja, o artista-docente estava em mim, impregnado em minhas vísceras sensoriais. Segue abaixo, imagem de algumas práticas artísticas na graduação.
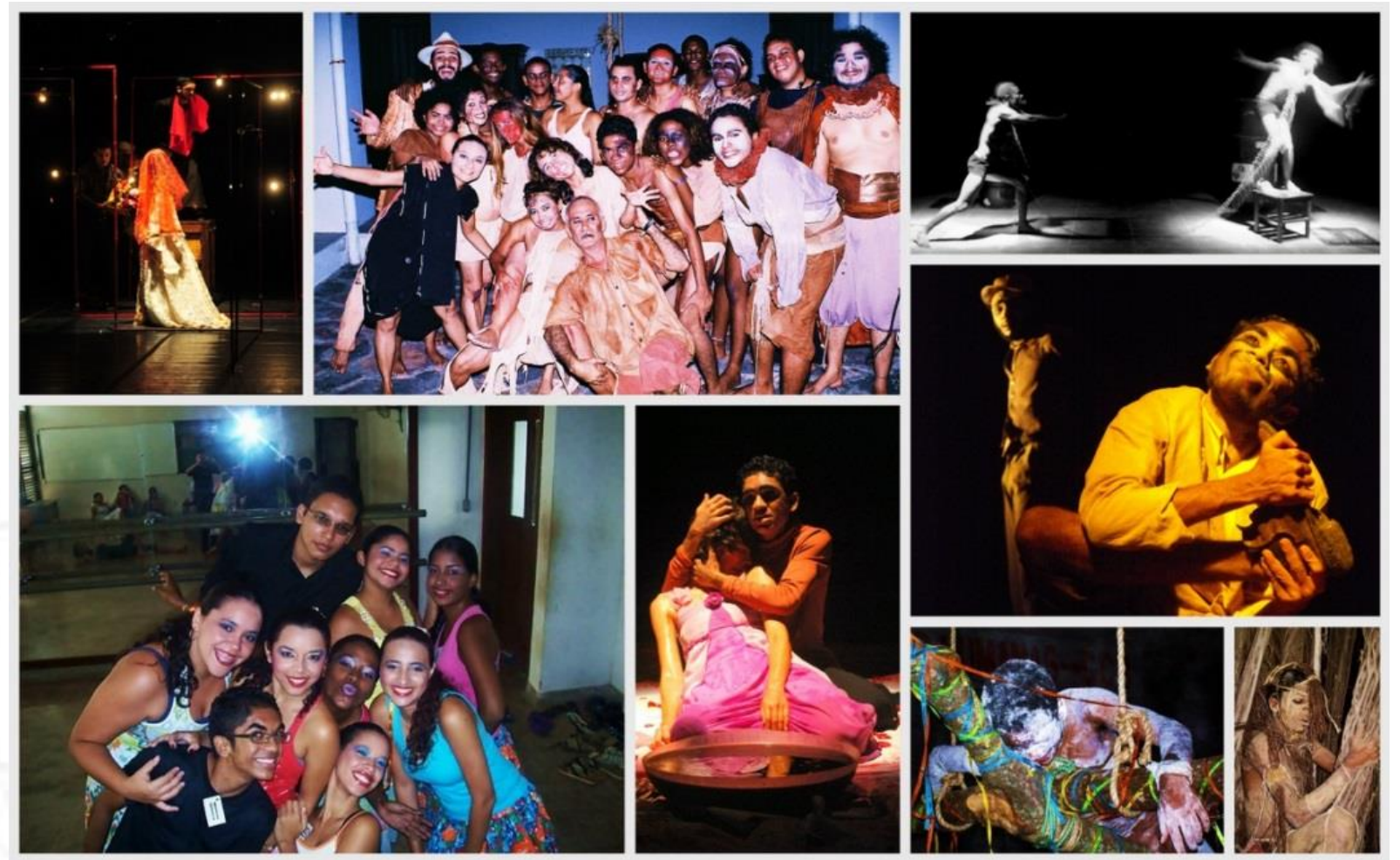

Figura 2 / Espetáculos e Experimentos Cênicos na Graduação em Teatro / Fotografia: Não-Memorável

Na estação [3] Monografia: apresentei os fluxos da construção do trabalho final da graduação, com seus seguintes capítulos. No primeiro capítulo, apresento a discussão sobre a formação docente na contemporaneidade, analisando a configuração curricular no que tange às atividades voltadas para a questão da prática e da formação artística, através da análise de projetos político-pedagógicos de diferentes Instituições de Ensino Superior. Nas partes seguintes, discuti sobre a experiência de caráter social e estético, assim como, as experiências da cena como condição 
de componente formador do docente em teatro. Finalmente, apresentei o processo de trabalho de dois coletivos cênicos, sendo um do Nordeste (Núcleo de Pesquisas Teatrais Rascunho, São Luís MA, espetáculo "Primeiro Amor") e outro do Sudeste (Cia. Teatro Documentário, São Paulo - SP, documentário cênico "Pretérito Imperfeito"), buscando identificar as possibilidades metodológicas do ensino de teatro descobertas por esses dois grupos a partir de suas experimentações cênicas. A monografia me fez perceber a relevância do exercício artístico para a formação docente, em diferentes contextos do Brasil. E a partir de então comecei a me questionar sobre os conceitos artista-docente, professor-artista e docente-pesquisador-artista.

Na estação [4] Espetáculo Primeiro Amor: relatei sobre a metodologia de trabalho do Núcleo de Pesquisas Teatrais Rascunho, grupo que fundei com a parceria de Abimaelson Santos no curso de Teatro da Universidade Federal do Maranhão, em 2010. Com formação de oito membros, fazíamos ensaios em salas de caráter teórico e prático. Para a construção do espetáculo utilizamos a prosa poética "Primeiro Amor" de Samuel Beckett, para montagem do monólogo, do qual fui o intérprete. Os grandes desafios foram: transformar a prosa poética em dramaturgia para a cena; pensar iluminação e sonoplastia com poucos equipamentos técnicos nas salas de ensaios; utilização das mesas e cadeiras da sala de aula como objeto de cena, que mais tarde, se tornaram cubos brancos para o espetáculo.

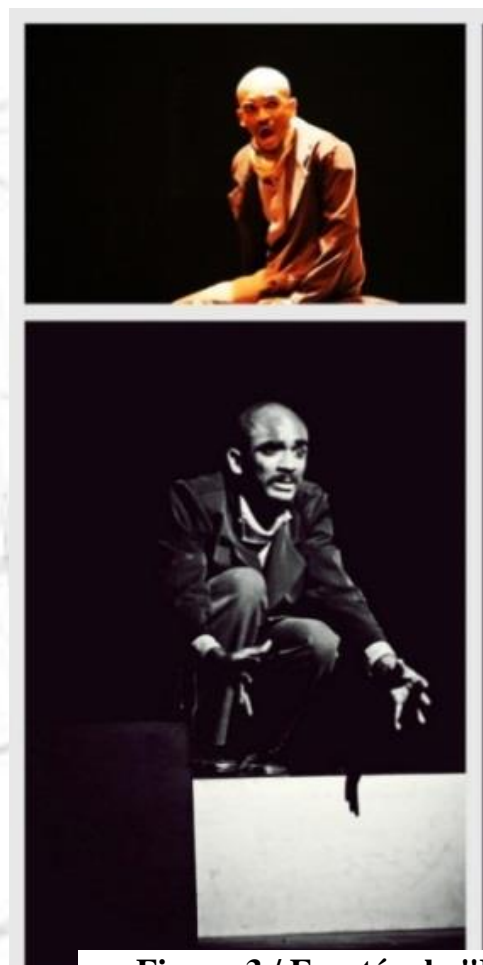

Figura 3 / Espetáculo "Primeiro Amor" / Fotografia: Carol Paraguassu e Leornardo Mendonça

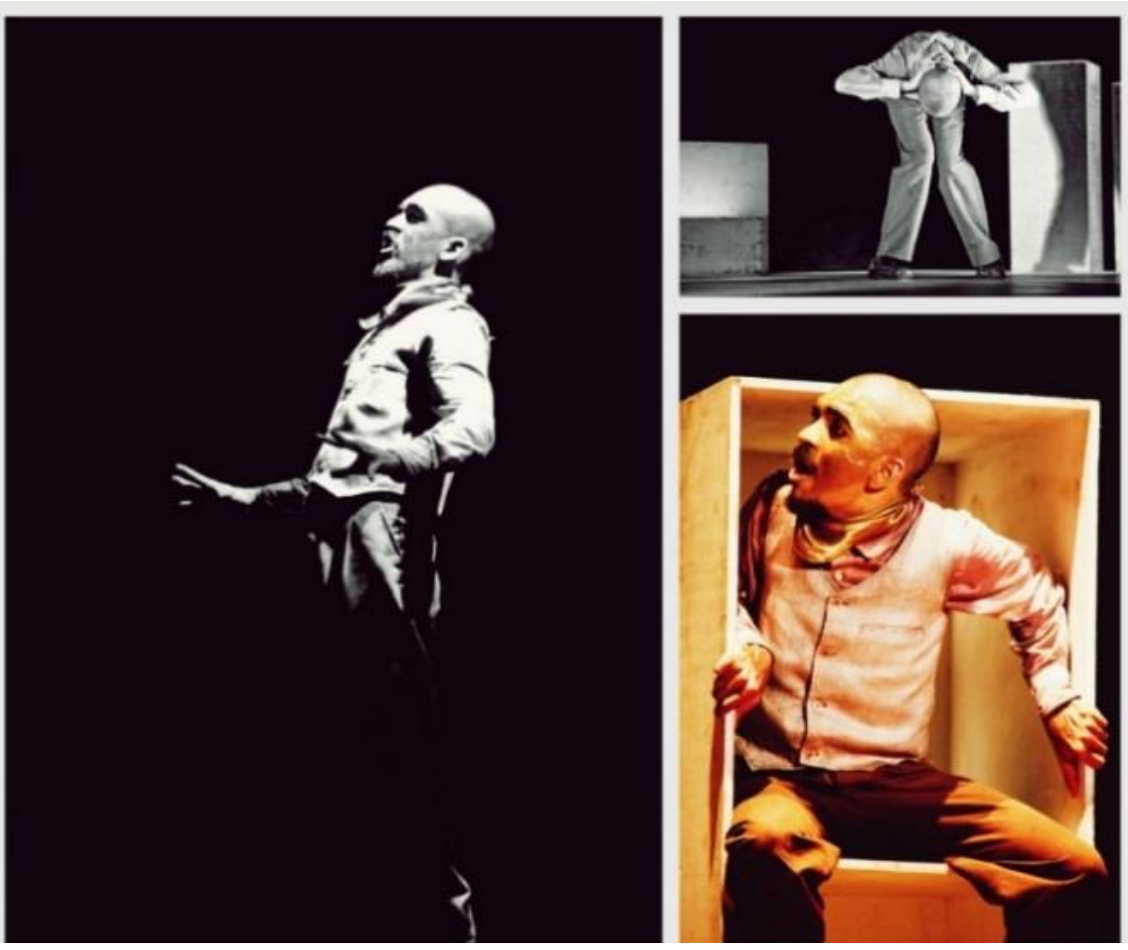


Na estação [5] Espetáculo Siameses: compartilhei também sobre a metodologia de trabalho do Núcleo de Pesquisas Teatrais Rascunho, utilizada nesse processo de criação. A dramaturgia de um autor Maranhense da nova geração, Zen Salles, usa a linguagem cômica e fantástica como metáfora para nos atentar à dificuldade humana em lidar com mudanças. A partir da discussão de identidade e alteridade presentes no texto, os atores criaram para a construção cênica Perfis das personagens na rede social Facebook, criando um espaço de interação com seus Amigos em seus Perfis. Sem saber o real objetivo das Páginas visivelmente falsas na rede social, e sem saber quem estava administrando, os "Amigos" das personagens (Irmão da Direita, Irmão de Esquerda, Monga e Mujer Barbada), adicionavam e conversavam com eles. Os diálogos nas redes sociais eram dos mais variáveis possíveis, portanto, tudo isso foi material cênico para a construção das personagens, com perguntas provocadoras do tipo: "Ligados pelo abdômen, como fazem para transar com sua(s) amada(s)?”. A narrativa transmídia foi a base principal para a criação. Segue abaixo, fotografias do espetáculo.
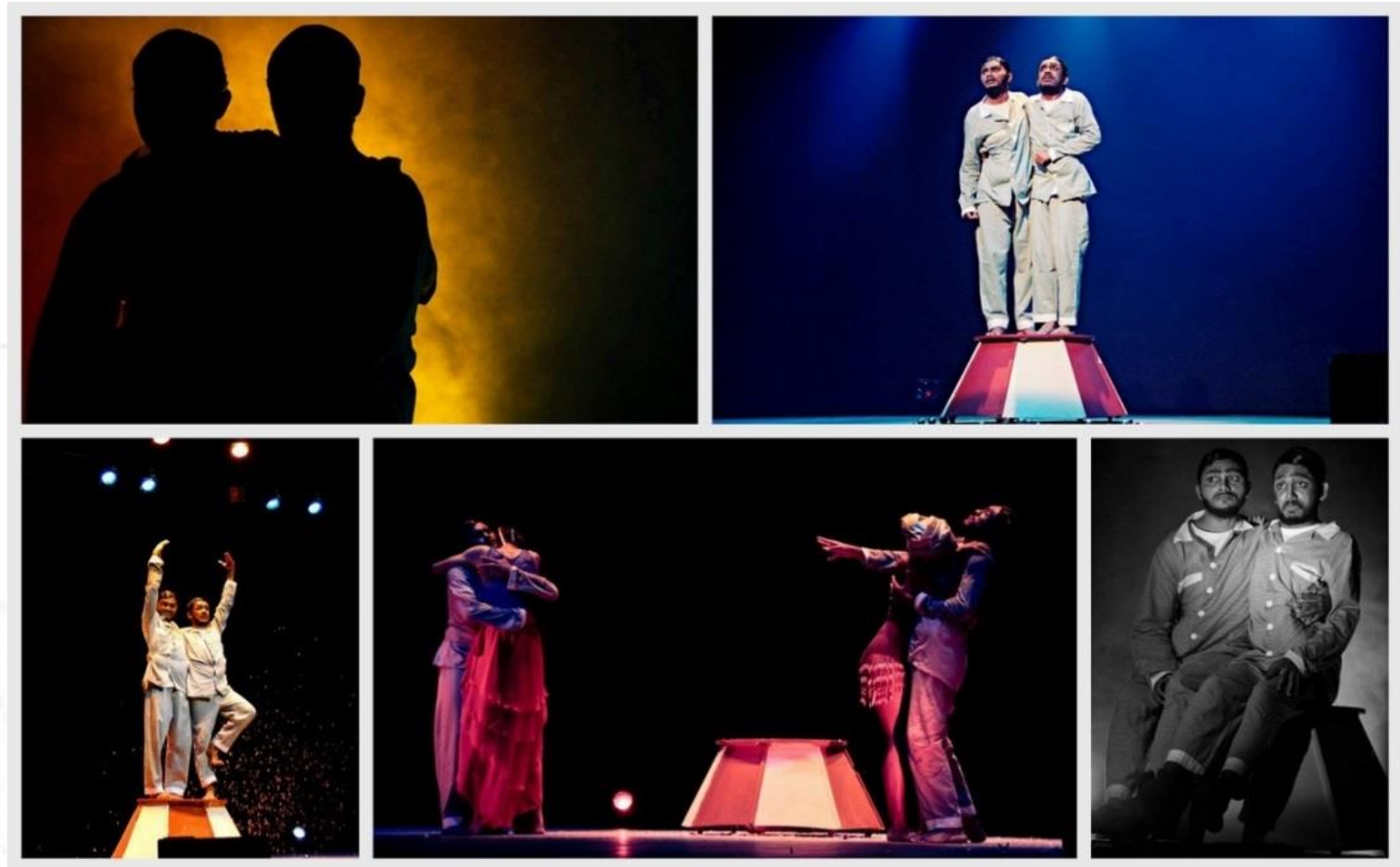

Figura 4 / Espetáculo "Siameses" / Fotografia: Leonardo Mendonça

Caro leitor, senti a necessidade, mesmo que breve, de relatar essas experiências práticas da desmontagem de forma escrita, como outro exercício de me ver como que diante de um espelho, ou melhor, exercitar a desmontagem na escrita e me auto descobrir ainda mais. 
A desmontagem "Experiências do sensível: travessias artísticas" apresentou em seu roteiro uma mostra de procedimentos basicamente técnicos, mas que em sua essência, revelou o(s) meu(s) olhar(es) diante das experiências cênicas que vivenciei, durante o percurso da minha trajetória com o Teatro, até os dias atuais. Este exercício proporcionou observar as técnicas, não somente pela prática do virtuosismo, mas como procedimentos vividos que possibilitaram encontrar o "não lugar" diante da minha formação enquanto artista-docente. O não-lugar, neste sentido, é o lugar expandido, com possibilidades de territórios e fronteiras diversas. A desmontagem cênica, seja qual for o roteiro ou temática discursiva, permite o reconhecimento das possibilidades de descoberta, tanto por parte do espectador, quanto, principalmente, por parte de quem a executa.

Levando em consideração que a desmontagem não revela somente os procedimentos estéticos e artísticos, mas também procedimentos pessoais e revelações testemunhais, esta estratégia cênica também expõe sensibilidades, medos, desafios, transgressões, atitudes, revelações, posturas, diálogos, pensamentos e posicionamentos pessoais que mostram a identidade ética e estética do artista.

Portanto, volto a afirmar que, apesar da escassa literatura a respeito da desmontagem cênica, a partir da minha experiência, percebo a relevância desse procedimento para a investigação dos processos criativos do artista-docente, tendo em vista que a desmontagem desnuda o artista e o mostra numa significativa presença, mesmo quando este opta por ocultar alguns procedimentos.

$\mathrm{Na}$ pesquisa em Artes de caráter prático, os processos criativos do artista-docente são geralmente coletados com registros, fotos, filmagens ou entrevistas. Contudo, observa-se também, que a estratégia da observação da desmontagem é outro campo profícuo de reflexão, haja vista as considerações de Ileana Diéguez (2010, p. 139) sobre as novas práticas contemporâneas. De acordo com a autora, "a presença é mais que objetual ou corporal, abarca a esfera do ethos e da ética". Com todos esses levantamentos, considero a presença da Ética e Estética na desmontagem fundamental para o mapeamento reflexivo acerca das novas abordagens e práticas contemporâneas e os aspectos constituintes no artista-docente.

\section{REFERÊNCIAS BIBLIOGRÁFICAS}

BILBÃO, José; MARTÍNEZ, Rosa; JIMÉNEZ, Lidia. Puesta em escena, comunicación e intermedialidad: estrategias de la mirada em las prácticas escénicas contemporâneas. Disponível em: http://www.revistalatinacs.org/12SLCS/2012_actas.html. Acesso em 01 ago. 2013.

DERRIDA, Jacques (1995). O teatro da crueldade e o fechamento da representação. In: A Escritura e a diferença. SP: Perspectiva, pp. 149-177. 
DIÉGUEZ, Ileana (comp.) (2009). Des/Tejiendo Escenas. Desmontajes: processos de investigación y creación. Cidade do México: Universidade Iberoamericana.

- (2010). Cenários expandidos: (Re) presentações, teatralidades e performatividades. Urdimento: Revista de Estudos em Artes Cênicas, n.15, Udesc, Florianópolis, pp. 135-148.

LARROSA, Jorge (2008). Desejo de realidade: experiência e alteridade na investigação educativa. In: BORBA, Siomara e KOHAN, Walter (orgs.). Filosofia, aprendizagem, experiência. Belo Horizonte: Autêntica, pp. 185-193.

LEAL, Maria Lucia (2013). Pedagogia da performance: uma experiência. In: TELLES, Narciso (org.). Pedagogia do teatro: práticas contemporâneas na sala de aula. Campinas, SP: Papirus, pp. 197-217.

PAVIS, Patrice (2010). A análise dos espetáculos. São Paulo: Perspectiva.

POE, Edgar Allan. Poemas e Ensaios. (Trad. Oscar Mendes e Milton Amado). São Paulo:

Globo, 1999. 3. ed. revista.

RANCIÈRE, Jacques (2010). Sobre la importancia de la Teoría Crítica para los movimientos sociales actuales. Estudios Visuales. nº7, Retóricas de la resistencia, pp. 82-89.

SALLES, Cecilia Almeida (2009). Gesto inacabado: processo de criação artística. São Paulo, FAPESP: Annablume. 